\title{
Vestígios memorialísticos de Anísio Teixeira: interlocuções com a educação jesuítica no início do século XX
}

\section{Memorialistic Vestiges of Anisio Teixeira: Interlocutions with Jesuit education in the early twentieth century}

Vestigios memorialistas de Anísio Teixeira: interlocuciones con la educación Jesuita a principios del siglo XX

Sheila CRIstina Monteiro Matos ${ }^{a}$

CARLOS ÂNGELO de MENESES SOUSA (iD ${ }^{\mathrm{b}}$

\section{Resumo}

Este trabalho resgata e analisa os vestígios e interlocuções advindos da influência jesuítica do percurso formativo de Anísio Teixeira na Bahia, a partir de uma abordagem qualitativa e de cunho memorialista. A pesquisa priorizou a análise de discursos e de fontes documentais. Estudando a vida pública e os fazimentos de Anísio Teixeira, rememora-se o seu legado na proposta de um modelo educacional sem privilégios, destinada democraticamente para todos, com destaque para o Movimento Escolanovista e a criação de escolas de tempo integral, em Salvador e em Brasília. Observa-se que um dos modelos propostos em sua vida pública, as escolas de tempo integral, inspira-se naquele que Anísio vivenciou durante sua educação básica, em colégios jesuítas baianos, com destaque para o desenvolvimento das faculdades intelectuais, morais, sociais e físicas dos alunos. Sua vivência com pragmatistas e escolanovistas, tanto no Brasil quanto no

a Universidade Católica de Brasília (UCB), Brasília, DF, Brasil. Bolsista do PNPD/Capes. Doutora em Educação, e-mail: sheilammatos39@gmail.com

b Universidade Católica de Brasília(UCB) e Cátedra Unesco de Juventude, Educação e Sociedade, Brasília, DF, Brasil. Doutor em Sociologia, e-mail: carlosangelos@yahoo.com.br 
exterior, cimentou uma concepção, tida como liberal, de uma Educação Integral laica para todos, não focada em filhos da elite, que, tradicionalmente, estavam presentes nos colégios jesuítas. Vale ressaltar que, durante as investigações, observamos um apagamento desse período jesuítico da memória anisiana, estigmatizado, inclusive, como indiferente, porém importante para a elucidação de questões que pairam na roda do pensamento educacional brasileiro.

Palavras-chave: Anísio Teixeira. Educação Integral. Jesuítas.

\begin{abstract}
This work rescues and analyzes the vestiges and interlocutions coming from the Jesuitical influence of the formative course of Anísio Teixeira in Bahia, from a qualitative and memorialist approach. Documentary research prioritized the analysis of speeches and documentary sources. Studying the public life and the works of Anisio Teixeira, his legacy is recounted in the proposal of an educational model without privileges, destined democratically for all, with emphasis on the Escolanovista Movement and the creation of full-time schools in Salvador and in Brasilia. It is observed that one of the models proposed in his public life, the full-time schools, is inspired by the one that Anisio lived during his basic educationin Jesuit schools in Bahia, with emphasis on the development of intellectual, moral, social and physical faculties of the students. His experience with pragmatists and Escolanovistas, both in Brazil and abroad, cemented a conception, considered as liberal, of an Integral Lay Education for all, not focused on the children of the elite, who were traditionally present in the Jesuit colleges. It is worth mentioning that, during the investigations, we observed a deletion of this Jesuitical period of Anisian memory, stigmatized, even as indifferent, but important for the elucidation of issues that lie in the wheel of Brazilian educational thought
\end{abstract}

Keywords: Anísio Teixeira. Integral Education. Jesuits.

\title{
Resumen
}

Este trabajo rescata y examina los vestigios e interlocuciones provenientes de la influencia jesuítica del recorrido formativo de Anísio Teixeira en Bahia, a partir de un abordaje cualitativo y de carácter memorialista. La investigación priorizó el análisis de discursos y fuentes documentales. Estudiando la vida pública y las acciones de Anísio Teixeira, rememes su legado en la propuesta de un modelo educativo sin privilegios, orientado democráticamente para todos, con énfasis enel movimiento "escolanovista" $y$ la creación de escuelas a tiempo completo, en Salvador y Brasília. Se observa que uno de los modelos propuestos en su vida pública, las escuelas a tiempo completo, se inspira en lo que Anísio experimentó durante su educación básica, en colegios jesuitas en Bahía, con énfasis en el desarrollo de facultades intelectuales, morales, sociales y físicos de los estudiantes. Su experiencia con los pragmáticos y escolares, tanto en Brasil como en el extranjero, consolidó una concepción, considerada liberal, de una 
educación integral secular para todos, no centrada en los hijos de la élite, que, tradicionalmente, estaban presentes en los colegios Jesuitas. Es de destacar que, durante las investigaciones, observamos una supresión de este período Jesuita de la memoria de Anísio Teixeira, estigmatizada, incluso, como indiferente, pero importante para la elucidación de temas que se centran sobre el sistema del pensamiento educativo Brasileño.

Palabras clave: Anísio Teixeira. Educación integral. Jesuitas.

\section{Introdução}

Anísio Spínola Teixeira (1900-1971) é uma das referências mais influentes na história do pensamento educacional brasileiro no século XX. Militou pela consolidação de um ideal pedagógico, apregoado a uma educação como instrumento de progresso e desenvolvimento para o país.

As ações político-pedagógicas de Anísio destacam seus elementos fundantes: o ideário consubstanciado no exercício democrático, a autonomia do indivíduo e a percepção de que o processo de escolarização poderia ser uma estratégia de desenvolvimento de cidadania para todos os alunos, especialmente os advindos de classes populares.

Os legados anisianos são evidenciados ao longo do estudo do pensamento educacional brasileiro. Ele foi Inspetor Geral de Ensino da Bahia, de 1924 a 1929; Diretor de Instrução Pública do Rio de Janeiro, de 1931 a 1935; reitor da Universidade do Distrito Federal (UDF), em 1935; conselheiro de ensino superior da UNESCO, em 1946-1947, na Europa; Secretário de Educação da Bahia em 1947 e Reitor e Vice-Reitor da Universidade de Brasília (UnB), de 1962 a 1964. Ele ainda trabalhou na Coordenação de Aperfeiçoamento de Pessoal em Nível Superior (CAPES), de 1951 a 1964, foi diretor do Instituto Nacional de Estudos Pedagógicos (INEP), de 1952 a 1964; criou o Centro Brasileiro de Pesquisas Educacionais (CBPE) e organizou a Revista Brasileira de Estudos Pedagógicos (MATOS, 2016).

Para entender o seu pensamento educacional, cuja tessitura perpassa por uma educação sem privilégios e com base democrática, torna-se fundamental recorrer à história da educação brasileira, engendrada em novos moldes que, por ora, surgiam 
no início do século XX. Como Brandão e Mendonça (2008) problematizam, no livro “Uma tradição esquecida: por que não lemos Anísio Teixeira?”, a riqueza de seu legado ficou por muito tempo obscurecida, motivada por estigmatizações de que ele era "educador liberal", influência da interação com o pragmatismo estadunidense quando estudou no Teacher's College na Universidade de Columbia, na década de 1920. Importante ainda é considerar o que elucida Gondra (2000, p. 11), que seria "possível encontrar Anísio em lugares onde ele não mais estivesse e, por intermédio de pegadas deixadas ou imaginadas, surpreender a flama, a labareda, a luz em pleno movimento”.

Anísio teve outras influências as quais, para o exercício da memória ${ }^{1}$, urge a necessidade de elucidar algo que ainda é pouco investigado ${ }^{2}$ : seu percurso formativo nos Colégios Jesuítas, instituições educativas tradicionais que gozaram de grande espaço político-ideológico e, não menos importante, de influência nas questões político-educacionais da época.

Os Colégios Jesuítas, no Brasil, foram fundados desde o período colonial e tinham como finalidade inicial proporcionar o processo de instrução aos gentios, bem como levar a fé cristã. Com o passar do tempo, obtiveram uma pedagogia sistematizada e respeitada ao adotar métodos e um currículo diferenciado aos alunos que lá eram educados (AZEVEDO, 1986; LACOUTURE, 1994; LEITE, 1949).

Nesse contexto, este trabalho busca refletir sobre vestígios e interlocuções advindos da influência jesuítica do percurso formativo de Anísio Teixeira. Possui uma abordagem qualitativa e apresenta cunho memorialista. A tipologia de fontes nesta pesquisa visa proporcionar a interpretação de vestígios propalados em diferentes fontes, como discursos, documentos e registros de entrevistas.

A investigação é movida por uma busca incessante de rememorar o passado, ressuscitar detalhes, discutir motivos, confrontar opiniões, analisando um período histórico marcado, conforme Brandão e Mendonça (2008, p. 11), por "educadores,

\footnotetext{
${ }^{1}$ Neste trabalho, o conceito de memória remonta à ideia de Ecléa Bosi (1994): perspectiva de reconstruir e reinterpretar os acontecimentos dos quais os sujeitos foram participantes de um determinado tempo histórico.

${ }^{2}$ Por exemplo, a biografia de Anísio Teixeira constante do sítio eletrônico do Centro de Pesquisa e Documentação de História Contemporânea do Brasil (CPDOC) da Fundação Getúlio Vargas (FGV), disponível em https://cpdoc.fgv.br/producao/dossies/ AEraVargas1/biografias/anisio_teixeira, não tece quaisquer comentários sobre sua formação jesuítica, enquanto estudo sistemático.
} 
em vários estados da federação, [que] militavam nas administrações públicas da educação desde a década de 1920”.

Para compreender os fundamentos de seus pensamentos, algumas pistas foram fornecidas a partir de leituras do movimento renovador brasileiro, que foi marcante em suas obras e publicações. Sobre a ação educacional jesuítica, que recebeu ao longo da educação básica, são significativas as correspondências publicadas no sítio eletrônico da Biblioteca Virtual de Anísio Teixeira ${ }^{3}$, e particularmente o conteúdo da fonte documental "Conferências Pedagógicas" da Missão da Companhia de Jesus (RENAUD, 1921).

A obra organizada por Renaud (1921, p. 7) se caracteriza como uma fonte primária, por ser um relatório de uma Semana Pedagógica conduzida por Ignácio de Azevedo e seus 39 companheiros, patronos da missão jesuítica "Brasil Septentrional". As sessões de trabalho foram oficialmente abertas por Marcelo Renaud, no Colégio Antônio Vieira, em Salvador, entre 20 e 27 de janeiro de 1921.

\section{A vida pública e os fazimentos ${ }^{4}$ de Anísio Teixeira: novo pensamento educacional}

Como um membro importante de uma geração de vanguarda que efetuava crítica a determinados aspectos da tradição jurídica, científica e liberal do século XIX (MONARCHA, 2001), Anísio Teixeira objetivou instaurar uma modernidade educacional e cultural, impactando uma sociedade da época que ainda valorava os costumes e mentalidades de séculos anteriores.

$\mathrm{Na}$ tentativa de engendrar uma experiência da modernidade protagonizada por sujeitos que comungavam de uma nova ordem, cuja apropriação de novos temas e problemáticas concernentes às questões da educação e das ciências eram urgentes e necessárias, Anísio Teixeira com Lourenço Filho e Fernando de Azevedo foram denominados “os cardeais da educação brasileira”, segundo a formulação de Afrânio Peixoto (apud MONARCHA, 2001, p. 8). Esses “cardeais” da educação

\footnotetext{
${ }^{3}$ Disponível em: <http://www.bvanisioteixeira.ufba.br/>. Acesso em: 02 jun. 2019.

${ }^{4}$ Expressão que, ao enfatizar ação e processo, deixa entrever um "híbrido de intelectual e de fazedor" (HEYMANN, 2005, p. 44).
} 
foram notoriedade no início do século XX, por adotarem um espírito cosmopolita e pensarem para além de um "Brasil velho" (p. 10).

Esses “cardeais”, liderados por Anísio Teixeira, elaboraram o Manifesto dos Pioneiros (1932), também conhecido como Manifesto dos Escolanovistas, inspirado em uma proposta de política educacional em que o aluno passava a representar o centro do processo de aquisição do conhecimento escolar, garantindo o respeito a sua individualidade e à criatividade inerente ao processo educativo, o que, para a época, era considerado transformador. Nesse sentido, conforme Matos (2017), o Movimento vislumbrava a formação completa aos alunos, consubstanciada na superação da dualidade da formação para a elite e para as classes populares, compreendendo atividades intelectuais, profissionais, artísticas, físicas e de saúde, congregando, paralelamente, ações de cunho ético-filosófico como: formação de hábitos, atitudes e o cultivo de aspirações.

Esses membros de uma vanguarda cultural sinalizavam uma perspectiva de "consciência de ruptura", indo ao encontro de posições renovadoras, como aponta o próprio Anísio Teixeira:

O facto da sciencia trouxe consigo uma nova mentalidade [...] Não há alvo fixo. A experimentação scientífica é um methodo de progresso literalmente ilimitado. De sorte que o homem passou a tudo ver em função dessa mobilidade [...] Elle ganhou o hábito de mudar, de transformar-se, de "progredir", como ele diz. E essa mudança e esse "progresso", o homem moderno o sente: é ele que o faz (TEIXEIRA, 1930, p. 4).

Ao se reportar ao Manifesto, Saviani (2008, p. 253) avalia que "mais do que a defesa da Escola Nova está em causa, no 'Manifesto', a defesa da escola pública". Verifica-se que, em plena década de 1930, Anísio Teixeira já defendia a necessidade de associar o mestre de classe à pesquisa educacional (MENDONÇA, 2008), organizando a escola com base no conhecimento científico disponível. No tocante ao binômio ciência versus arte de educar, sinaliza Teixeira (1977, p. 46) que:

Não se trata, pois, de criar propriamente uma 'ciência da educação', que, no sentido restrito do termo, como ciência autônoma, não existe nem poderá existir; mas de dar condições científicas à atividade educacional, nos seus três aspectos fundamentais - de seleção de material para o currículo, de métodos de ensino e disciplina, e de organização e administração das escolas. Por outras palavras: tratase de levar a educação para o campo das grandes artes já científicas - como a 
engenharia e a medicina - e de dar aos seus métodos, processos e materiais a segurança inteligente, a eficácia controlada e a capacidade de progresso já asseguradas às suas predecessoras relativamente menos complexa.

No fragmento anterior, Teixeira já propõe, para a roda de embates, que as práticas educativas poderiam ser beneficiadas com uma relação intrínseca com o progresso da Ciência. Tal situação não deveria ser precipitada, mas cautelosa. Seria uma espécie de mudança paulatina para o professor, considerando buscar a cooperação na transição da educação, do seu atual empirismo para um estado progressivamente científico (TEIXEIRA, 1977).

Uma das bases teóricas e epistemológicas, para tal redimensionamento da mentalidade da época, foi ao encontro da filosofia do estadunidense John Dewey ${ }^{5}$ (TEIXEIRA, 1977, p. 66), que perscrutava em um esforço de continuada conciliação (ou reconciliação) e ajustamento (ou reajustamento) entre a tradição e o conhecimento científico; entre as bases culturais do passado, ameaçadas de outro modo de dissociação e estancamento e o presente que flui, cada vez mais rápido e rico, para um futuro cada vez mais precípite e amplo. Ou seja, entre o que já foi e o vir a ser, de modo a permitir, e até a assegurar, integrações e reintegrações necessárias do velho ao novo, já operante quando não ainda dominante.

Nesse ínterim, a perspectiva experimentalista, própria do pragmatismo americano, passa a marcar o pensamento educacional de Anísio Teixeira. A escola não poderia ser uma preparação para a vida, mas sim a própria vida. Ele defendia a formação integral da criança. Logo, a educação deveria ter como meta a construção de um adulto civilizado, pronto para o progresso e para o desenvolvimento da sociedade (MATOS, 2016; TEIXEIRA, 2007).

Observamos, ainda, que a filosofia de John Dewey reforçava uma possível precariedade do mundo, fundando a interpretação do homem e do seu meio e o sentido da vida humana no próprio risco e aventura do tempo e da mudança. Seria o que Anísio Teixeira sempre alertava quanto ao presente que seria uma junção entre um "teimoso passado" e um "insistente futuro" (TEIXEIRA, 1955, p. 3-27).

\footnotetext{
${ }^{5}$ Anísio Teixeira leu com afinco e constância o filósofo John Dewey, com quem conviveu academicamente durante seus estudos nos Estados Unidos. Conforme Nunes (2010), a fidelidade de Anísio ao pensamento de Dewey se desdobrou em suas publicações, traduções e na sua própria prática política.
} 
Apesar de o Manifesto ser de 1932, o auge histórico dessa concepção no cotidiano pedagógico das escolas públicas e privadas do país aconteceu a partir da década de 1950, quando o Centro Educacional Carneiro Ribeiro (CECR) foi construído, em Salvador (BA). A perspectiva democrática teve por base a educabilidade humana, na qual o processo educativo foi concebido como deliberado e progressivo na formação do indivíduo (TEIXEIRA, 1996).

O CECR era destinado ao nível primário, sendo composto por quatro escolas-classe e uma escola-parque, seguindo a proposta de alternar atividades intelectuais (em um período) com atividades práticas, como artes aplicadas, industriais e plásticas, além de jogos, recreação, ginástica, teatro, música e dança em outro período. O modelo de estrutura do Programa também foi replicado para a atual Capital Federal, Brasília-DF, conforme Teixeira (1961, p. 195-198):

Educação primária a ser oferecida em Centros de Educação Elementar, compreendendo: [...] 'Escolas-classe' - para a educação intelectual sistemática de menores, nas idades de 7 a 14 anos, em curso completo de seis anos ou séries escolares; 'Escolas-parque' - destinadas a completar a tarefa das 'escolas-classe', mediante o desenvolvimento artístico, físico e recreativo da criança e sua iniciação no trabalho, mediante uma rede de instituições ligadas entre si [...] Os alunos frequentarão diariamente a 'escola-parque' e a 'escola-classe', em turnos diferentes, passando 4 horas nas classes de educação intelectual e outras quatro horas nas atividades da 'escola-parque', com intervalo para almoço.

Nessa ambivalência de presente/passado/futuro, na visão de Anísio Teixeira, a educação do século XX deveria ser balizada em uma perspectiva de pensar o lavrador - camponês, ainda alijado de sua situação histórico social, num trabalhador e protagonista da nova conjuntura político e social da República.

Destaca-se, ainda, um dos legados de Anísio Teixeira: as atuais estratégias de fomento da educação integral têm como uma de suas mais relevantes referências o Movimento dos Pioneiros, bem como os modelos educacionais do CECR e das escolas públicas de Brasília:

Anísio Teixeira, um dos mentores intelectuais do Manifesto dos Pioneiros da Escola Nova, pensando na implementação de um Sistema Público de Ensino para o país, propunha uma educação em que a escola desse às crianças um programa completo de leitura, aritmética e escrita, ciências físicas e sociais, e mais artes industriais, desenho, música, dança e educação física, saúde e alimento à criança, visto não ser 
possível educá-la no grau de desnutrição e abandono em que vivia (BRASIL, 2009, p. 15 , grifos nossos).

Nesta seção enfatizamos fazimentos de Anísio, particularmente a partir da década de 1930, que promoveram legados para o pensamento educacional e para a implementação de políticas públicas na área de educação. A seguir, buscaremos compreender um pouco mais sobre sua educação básica, refletindo sobre o pensamento pedagógico jesuítico.

\section{O Pensamento Pedagógico Jesuítico}

A Ordem da Companhia de Jesus foi fundada por Inácio de Loyola ${ }^{6}$, em 1534, constituindo-se um marco histórico na consecução das ideias pedagógicas pelo mundo ${ }^{7}$. Seus principais intelectuais eram movidos pelo ideal cristão de levar o Evangelho de Cristo aos novos gentios.

O trabalho missionário dos jesuítas influenciou a história do pensamento educacional brasileiro, contando com o apoio financeiro do Rei de Portugal e das autoridades locais da época. Vale destacar que outras Ordens (beneditinos, franciscanos, capuchinhos, carmelitas etc.) se deslocaram para o Brasil com a finalidade de contribuir no processo de colonização, porém operaram de forma dispersa e intermitente, na maioria das vezes, sem apoio e proteção oficial, dispondo, apenas, de parcos recursos financeiros e de pessoal (GUMIEIRO, 2013).

No Brasil, o grupo tem sua chegada em 1549, chefiado pelo padre Manoel da Nóbrega. A inserção dos jesuítas no Brasil-Colônia envolve uma análise imbricada, entre si, dos elementos: colonização, educação e catequese (SANTOS, 2017; TOLEDO; RIBAS; SKALINSKI JUNIOR, 2012). Cabe, nesta investigação,

\footnotetext{
${ }^{6}$ Inácio de Loyola nasceu em 1491, no território basco espanhol. Em 1521, foi gravemente ferido em um combate real, onde guerreava na Praça de Pamplona, então dominada pelas tropas francesas que invadiram a Espanha. No processo de descanso absoluto em razão de ordem médica, Loyola passou a desenvolver leituras de obras, cujas temáticas eram biografias de santos. Sentiu-se recrutado e tomado por essas leituras. Almejando uma educação superior mais densa, foi a Paris. Estudou Gramática, Arte, Filosofia e Teologia (LOYOLA, 2005).

${ }^{7}$ Loyola escreveu as Constituições (61 capítulos e 827 artigos) em 1550, cujo objetivo era uniformizar a ordem jesuíta nos diversos locais do mundo.
} 
imprimir um olhar dialético para além das aparências, verificando as contradições supostamente delineadas entre esses três elementos. Assim, o diálogo com esse tempo histórico pretende fomentar o desvelamento daquilo que foi perpetuado como a sacralização de determinadas chaves de leitura, disseminadas ao longo dos estudos em História da Educação.

$\mathrm{Na}$ assertiva de Saviani (2008), a assistência da Coroa portuguesa favoreceu a primazia do monopólio e da hegemonia na educação nos dois primeiros séculos da colonização $^{8}$. $\mathrm{Na}$ tentativa de realizar um processo educacional vinculado às bases doutrinárias da igreja católica, os inacianos foram trilhando uma didática propositiva sob a égide da Pedagogia do Ratio Studiorum que lhes conferiu hegemonia.

A referida proposta didático-pedagógica, tornada pública em 1559, foi planejada minuciosamente no interior da Ordem jesuítica, cujos cânones foram adotados pelos colégios jesuítas do mundo inteiro. Era sistematizada a partir dos estudos humanistas, cujos aspectos formativos se atentavam para os costumes, conduta e virtudes. O vocábulo latino ratio significa razão, plano, ordem, regra. Era, pelo Ratio, que havia um conjunto de normas que definiam saberes a serem ensinados e também condutas a serem inculcadas. Mais do que isso, consistia "em um conjunto de práticas que permitiam a transmissão desses saberes e a incorporação de comportamentos, normas e práticas” (CASTRO; SILVEIRA, 2016, p. 41).

Por seu turno, a palavra studiorum se traduz como modo, maneira, forma de fazer. Sabe-se que o plano educacional formulado pelos jesuítas constituiu um parâmetro curricular, cujo esboço didático-pedagógico transmitia o exercício da leitura e escrita para os gentios, conjugados a oficinas de marcenaria, agricultura e funilaria (MALLMANN, 1986). Embora tais feitos fossem realizados, alguns autores da literatura criticavam veementemente a tal estratégia didática, pois alegavam que esses métodos falseavam propostas de aculturação, uma vez que havia a imposição da moral católica, dos costumes e das convenções europeias aos indivíduos.

O próprio Anísio exaltou a proposta pedagógica jesuítica, em um cenário em que esse ideário era visto como antiquado, na década de 1920:

\footnotetext{
${ }^{8}$ Frisa-se que, em 1759, os jesuítas foram expulsos do Império português.
} 
Brevemente responderei que um dos motivos principais [da solidez do ideário jesuítico] é a seleção de capacidades e o superior preparo intelectual da Companhia. Os jesuítas, os de ontem, como os de hoje, são frutos desse Ratio Studiorum - tão sólido e firme - que por 4 séculos, quase sem outra transformação senão a que lhe vinha de sua própria vitalidade - vem formando sábios sem conta. [...] Afinal desse Ratio assim alcunhado de imóvel, é que desabrocham estas inteligências privilegiadas que nos cercam, e ainda é hoje esse um dos segredos da vitória pedagógica dos jesuítas (TEIXEIRA, 1925, p. 593, grifos nossos).

Para melhor entender do que se trata a proposta pedagógica jesuítica, decidimos utilizar, como fonte documental, o registro das Conferências Pedagógicas da Missão da Companhia de Jesus do Norte do Brasil (RENAUD, 1921), que englobava diretrizes e recomendações a todos os colégios jesuítas no Brasil. Era uma prática recorrente da Companhia de Jesus realizar encontros periódicos para avaliar sua ação pedagógica e formação de seus professores, em vista de averiguar a aplicação de seus princípios educacionais, bem como atualizar sua prática pedagógica à luz desses mesmos princípios, frente às demandas históricas e de cada localidade cultural em que se desenvolvia sua ação educacional.

Este documento se divide em diferentes teses, desenvolvidas em dissertações ou em relatórios elaborados por comissões que compunham prefeitos, professores e reitores dos colégios. Na carta do Superior da Missão, destinada aos reitores dos colégios jesuítas, há um fragmento que aponta aquilo que se esperava dessas conferências pedagógicas:

Rogo, pois a todos que, com verdadeiro interesse e zêlo fervoroso pela bôa formação e educação da juventude, ministério tão próprio da Companhia, estudem diligentemente, cada um conforme suas aptidões, conhecimentos e experiência, os assumptos das theses e dêem, por escripto, aos membros da respectiva Commissão ou aos relàtores as observações, indicações, indústrias, etc. que possam auxiliar o trabalho. Estou certo que será éste de resultados surprehendentes para o bom andamento dos Collégios, se todos os NN concorrerem conscienciósamente com diligencia e zêlo para o feliz êxito destas conferências pedagógicas (RENAUD, 1921, p. 12).

Essas conferências tinham como objetivo realizar trocas de experiência entre os professores da Ordem, bem como alinhar, coletivamente, o ideário pedagógico proposto pelo método jesuítico de ensinagem. Não se propunham reformulações, nem alterações ou medidas que fossem de encontro à proposta original do método. 
Estas conferências não terão a pretensão de operar reformas, nem de descobrir novos systemas de educação ou ensino; tendo, como temos, sólida base pedagógica no Ratio e nas tradições seculares da Companhia, o nosso maior anhelo deve consistir em accommodar-nos com a maior perfeição possível a essas leis, cheias de prudência e de experiência, para assegurar o êxito de nossos trabalhos nos Collégios (RENAUD, 1921. p. 18).

$\mathrm{O}$ documento $\mathrm{V}$ da conferência jesuítica, intitulado "O educador da Companhia nos Collégios", dissertado pelo padre Manuel Pacheco, sinalizava sobre as virtudes que o educador da Companhia deveria trazer consigo. Assim, além de uma formação intelectual e educativa, o jesuíta deveria exercitar uma vida de oração em constante vigilância:

As virtudes que no educador da Companhia devem acompanhar o desenvolvimento da sua actividade intellectual e educativa; e, nomeádamente ordena: que, antes de tudo, examine e considere o Superior, se os prefeitos, no Collégio, são convenientemente orientados na vida espiritual, e se, no desempenho de seu dever de educadores, não se limitam a uma simples e estéril vigilância, mas o fazem consistir principalmente na prática da oração e do bom exemplo, no exercício da caridade e mansidão christã, no espírito de sacrifício, prudência, fortaleza e assíduo trabalho ... rite perfungantur (praefecti morum) ofício suo, non merae vigilantiae, sedo ratione, bono exemplo, caritate et mansuetudine Christi, spiritu sacrificii, prudentia et fortitudine et indefesso labore [... ] (RENAUD, 1921, p. 21).

Em outro trecho do documento, verificamos, também, a solidez epistemológica e metódica sobre o perfil deste educador na Ordem Inaciana:

Por isso, ou o educador da Companhia é um homem dissipado e alheio à vida interior, e nêste caso a sua influência educativa há de adoecer forçosamente de defeitos muito graves que tornem infecundo seu trabalho; ou é um homem recolhido, dado à oração e a união com Deus; e então os alumnos, que ainda sejam ineptos e quasi cegos para tudo quanto sejam lettras, têem vista apurada para descobrir em seu educador as virtudes como os defeito, a pouco trecho, hão de acabar de reconhecer em seu prefeito e professor o homem sobrenatural, a cuja acção educativa se abandonarão com tanta maior confiança quanto maiores e mais brilhantes forem as manifestações de espírito interior e de oração que nêlles admirarem (RENAUD, 1921, p. 34).

A concepção da educação, neste documento, é retratada como um conjunto de elementos que agregam as faculdades físicas, intelectuais e morais no aluno, aproximando-se à concepção liberal de educação integral, que teve o Movimento 
Escolanovista de 1932 como principal marco, consoante Matos (2017) ${ }^{9}$, Coelho e Menezes $(2007)^{10}$.

A concepção jesuítica seria uma possibilidade para transformar o homem todo em uma nova entidade, cujo coração e mente devem estar em sintonia rumo a uma divindade, isto é, Jesus Cristo (RENAUD, 1921). Na análise do documento, observamos que, embora se forje no aluno os conhecimentos historicamente acumulados na sociedade, tal ação torna-se secundária, pois prioritário, nos colégios jesuítas, é potencializar moralmente e espiritualmente a criança ou o adolescente. Está frisado no documento um pensamento de Santo Inácio que reverbera tal assertiva:

Hão de os educadores da Companhia aproveitar, com arte muito natural, todas as occasiões que se oferecem nos labores escolares, de semear germens de virtude no coração do discípulo, com uma palavra, com uma observação ou conselho a propósito. Uma phrase da preleç̧ão, um episódio mais curioso do auctor explicado, o assumpto de um thema, a história, até a mythologia pagã, tudo lhes ha de dar ensejo a pequeninas e rápidas lições de moral, sem impertinência, sem fastio, mas com muito gôsto dos alumno. Desta arte vae penetrando de mansinho na alma da creança a semente que depois desabrochará em fructos de benção (RENAUD, 1921, p. 23).

A temática da Ciência é conduzida pelo entendimento de que deve haver uma união entre "sciência, educação moral, das letras com a formação do carácter" (RENAUD, 1921, p. 24). A junção desses elementos, na prática pedagógica, possibilitaria transformar o ensino e a ciência em um meio de regeneração e elevação da humanidade.

Outro tema recorrente, neste documento, reforça a ideia de que a educação religiosa é um esteio para as demais práticas educativas que são realizadas pela Ordem. Por meio dela, os meios tentam atingir um fim memorável na formação de crianças e jovens, possibilitando, conforme o documento, preparar o homem para ocupar dignamente seu lugar na família, na sociedade, nas dificuldades da vida e na consecução do seu bem-estar.

\footnotetext{
${ }^{9} \mathrm{Na}$ concepção liberal, a educação integral defende o propósito de uma educação pública, perpassando por uma formação completa do ser humano. Essa concepção entende que a formação completa da criança, via educação, teria como meta a construção de um adulto civilizado, pronto para o progresso e para o desenvolvimento da sociedade.

${ }^{10} \mathrm{~A}$ educação integral considera o indivíduo na sua pluralidade, como um ser que deve desenvolver as suas capacidades físicas, psicológicas, intelectuais, morais.
} 
A ação de ensinagem no Ratio é vista como algo desafiador no trato com a formação de alunos, pois os discentes chegam aos colégios com posturas e comportamentos ainda dissociados dos objetivos que a escola propõe como alternativa de formação educacional. Assim, adequar métodos, ideias, tendências e a relação professor-aluno passam a ser um processo de esteio primordial na educação continuada dos jesuítas.

Um dado importante neste documento é o exercício da disciplina. Tal tema é ainda caro para uma incursão nessa seara, pois tensionar acerca do exercício da disciplina é retomar um debate na fronteira que abrange os limites, as condições, as obrigações, os temores e as possibilidades do disciplinar. No intuito de elucidar esse fragmento do documento para além da intenção de quem o produziu, percebemos que há uma relação de conquista e apropriação constante dessa ação disciplinante. Tal conquista remete-nos a assegurar que os alunos egressos dessas instituições jesuítas obtinham grande gama de conhecimentos gerais, pois construíram, ao longo dos anos letivos, hábitos de estudo pautados em uma disciplina apreendida pelos professores jesuítas. No excerto a seguir, constatamos que:

A disciplina é a base da bôa educação. Representa, em linguagem christã, o conjunto de normas e práticas de uma vida regrada e bem procedida. A linguagem ordinária vem confirmar este modo de ver, quando dá a etymologia da palavra toda a sua fôrça, ao dizer de um homem, que foi educado sob uma bôa, alta e santa disciplina (RENAUD, 1921, p. 31).

O aspecto ligado à afetividade no processo educativo é retomado neste documento, cuja referência é lembrada como um elemento importante e salutar em um exercício de aprendizagem significativa. Segundo os jesuítas, a conquista do coração, do ponto de vista da relação humana, seria calcada em uma investidura para o sucesso e para um aprender com comprometimento:

É mister que os nossos alumnos nos amem, que sympathizem comnosco; é indispensável que apreciem a nossa convivência, que folguem de nos escutar na classe, como nas horas do recreio... Confesso que nem todos dispomos desses dotes de seducção bem entendida, que fazem de quem os possúe verdadeiros centros de attracção, em toda a parte onde se encontram; mas, por isso mesmo, não é em todos da mesma eficácia. Uma coisa, porém, é igualmente certa: e é o ser sympáthico aos alumnos e até estimados por èlles constitúe uma condição necessária para todo e qualquer bom resultado no campo da educação (RENAUD, 1921, p. 39). 
Ainda no campo de análise da relação humana e afetividade:

Ora a creança não sympathizará jàmais com o educador que a olha friamente ou passa indifferente a seu lado; que não tem para ella senão palavras de doesto ou reprehensão; que não lhe mostra interesse; que não procura satisfazer legítimos e innocentes desejos, podendo-o fazer; que não lhe patenteia pràticamente estima e amôr. O - si vis amari ama, - é, no presente caso, de uma realidade flagrante (RENAUD, 1921, p.40).

As relações comunicacionais e o procedimento de intervenção pedagógico deveriam acentuar um fazer pedagógico significativo, cujo êxito necessita ser balizado na figura de autoridade em que o educador deve legitimar. Nesse contexto, não há de se confundir autoridade com autoritarismo:

No que levo dicto até aqui suppõe-se o exercício constante daquela virtude, dessa energia moral, no sentido rigoroso da palavra, que robustece a prática das outras virtudes e firma o caracter, dando-lhe uma têmpera de aço para não desfallecer no meio das maiores difficuldades, para arrostar todos os perigos, para estar sempre prompto a todos os sacrifícios e até heroísmos que a missão nobilíssima de educador exige. Por êste modo fica manifesto quão errados andam os que confundem a virtude da fortaleza com a rispidez no trato ou com um tom e modos auctoritários e de sobranceria e fôrça, que, longe de se impôrem e fazerem estimar e amar, afastam e irritam (RENAUD, 192, p. 44).

As conferências pedagógicas também trataram do respeito às individualidades dos alunos, considerando métodos e técnicas diversificadas de ensino com o propósito de alcançar uma verdadeira aprendizagem e uma exímia apropriação do conhecimento. No excerto a seguir, constatamos tal situação:

Aprendamos nós a nunca desesperar, continúa o mesmo auctor: quaesquer que sejam os defeitos e prevaricações dos nossos alumnos, elles não são seres incuráveis; deixemos subsistir sempre um raio de esperança; deixemos cahir sempre em seus corações alguma semente do bem, que pode germinar ainda e crescer e produzir talvez um grande character [...] Jesus sabia individualizar: não destruía a originalidade, não mutilava a personalidade, mas adaptava seus méthodos aos differentes caracteres (RENAUD, 1921, p. 46).

Não podemos esquecer que essa fonte documental foi produzida e pensada em um determinado tempo histórico. Todavia, seus elementos denotam atributos para além de estigmas sobre métodos conservadores e tradicionais: a pedagogia jesuítica, ainda que majoritariamente para uma elite, priorizava a conjunção dos 
aspectos morais, intelectuais e físicos, com a formação de hábitos e de atitudes, com destaque para a ação do professor, visto como educador. Como essa pedagogia influenciou Anísio Teixeira?

\section{A influência jesuítica em/de Anísio Teixeira}

Algumas pistas nos são oferecidas para compreendermos os fundamentos que consubstanciaram o ideário anisiano no início do século XX. Embora o país passasse por grandes transformações com o advento do republicanismo, no final do século XIX, persistiam amarras no campo educacional, como a ineficiência de implantar um sistema nacional de ensino, bem como um agravante déficit histórico em matéria de educação. Saviani (2008, p. 167-168) salienta que "além das limitações materiais, cumpre considerar, também, o problema relativo à mentalidade pedagógica".

O problema da mentalidade pedagógica caracterizava-se com dissonâncias no tocante à forma e ao conteúdo epistemológico das ideias pedagógicas (concepção de homem, de mundo, de sociedade e de educação). Assim, conforme Saviani (2008), o início do século XX denota três mentalidades, quais sejam: tradicionalista, liberal e cientificista. Sucintamente, vemos, na arena de lutas, o aspecto do financiamento e da mentalidade pedagógica como centro de ponderações necessárias para se promover uma nova agenda educacional para o novo porvir que chegara.

No contexto dessa arena da política educacional, no início do Século XX, havia os Colégios Jesuítas fundados pelos inacianos portugueses, que detinham três instituições no Nordeste brasileiro: o Colégio Antônio Vieira em Salvador (BA), o Instituto São Luiz Gonzaga em Caitité (BA) e Colégio Nóbrega em Recife (PE). Esses eram regidos pelo Ratio Studiorum, o principal documento da doutrina educacional jesuítica.

Por sua parte, Anísio nasceu de uma família afortunada de bens materiais no sertão baiano. Averiguando sobre sua biografia em família, conforme Santos (2017), constatamos que houve um grande conflito pessoal de Anísio Teixeira com seus familiares, em razão de suas escolhas. 
Caetité, sua terra natal, era uma cidade de prestígio no campo intelectual. Havia uma escola para a formação de professores bastante conhecida na região. Algo interessante a se destacar era que o pai de Anísio, Deocliciano Pires Teixeira, médico que servira na campanha do Paraguai (TEIXEIRA, 1989) e político, ajudou a fundar o Instituto São Luiz Gonzaga (1911-12) 11, conhecido como o "Colégio dos Padres". Segundo o padre Ferdinand Azevedo, havia uma disputa de poder no que tange à educação, tanto em Caetité, quanto em Salvador, pois protestantes também estavam fundando colégios (AZEVEDO, 1986).

Em Caetité, o itinerário educacional de Anísio Teixeira teve início na escola primária de Dona Maria Teodolina das Neves Lobão, considerada a primeira professora municipal a ministrar classes para meninos. Entre 1911-1912, Anísio Teixeira foi aluno do Instituto São Luiz Gonzaga. Posteriormente, foi transferido para dar prosseguimento nos estudos secundários na capital Salvador, no Colégio Antônio Vieira, em 1913-1914 (SANTOS, 2017, SAVIANI, 2008; NUNES, 2010).

Os colégios jesuítas tinham como público-alvo a elite regional, seguindo o princípio inaciano de instruir àqueles que detinham posses e condições sociais, para que fossem multiplicadores para os despossuídos. Os colégios tinham excelentes estruturas físicas (laboratório, museus, salas de leitura etc.) e detinham um corpo docente qualificado, com professores renomados, provenientes de formação universitária internacional, notadamente o grupo dos exilados da Província Portuguesa, conforme Sousa (2016).

O Colégio Antônio Vieira desfrutou, desde suas origens, até os dias de hoje, de um largo prestígio e reconhecimento entre as melhores instituições educacionais privadas da Bahia (BRITTO; MENEZES, 2016; SOUSA, 2017). A formação inicial humanística clássica obtida, a partir da ordem Inaciana, foi relevante para impregnar uma marca de um alicerce, cuja expressão é a educação do pensamento. Ilustramos, tal assertiva, no excerto que se segue:

Recebemos, nesses collegios de jesuítas, espalhados por toda parte e sempre idênticos, onde nos formamos, mais que uma instrucção. Tivemos uma educação

\footnotetext{
${ }^{11}$ Essa fundação data do período em que houve o retorno dos jesuítas ao Nordeste brasileiro, mais especificamente à Bahia. Tal expulsão da Ordem de Portugal foi em razão da queda da Monarquia e na instauração do Republicanismo (1910).
} 
do pensamento. Deram-nos vistas de conjunto lucidas e aprofundadas sobre a philosophia, communicam-nos, um pouco, os nossos mestres, os segredos desse methodo espiritual que constitui em toda parte a força poderosa do jesuíta e sobretudo, nos deram o grande complemento educacional indispensável - uma crença alicerçada com segurança na razão e na inteligência (TEIXEIRA, 1924, p. 2).

Porquanto, parece oportuno afirmar que sua formação foi adensada por um espírito científico e filosófico, cujas bases doutrinárias o forjaram como um grande intelectual que marcaria as ideias pedagógicas no século estudado.

Há outros fragmentos do discurso de Anísio que rememoram os benefícios intelectuais que foram apropriados durante o período em que viveu no colégio. Uma mescla de dúvidas, anseios, memórias e gratidão são evidenciados na sua fala, que se segue:

Sua philosophia, sua orientação para a vida, a clareza e o methodo do seu pensamento, foram forjados aqui. Aqui elles receberam, como nós outros mais antigos recebemos, essa disciplina psychologica que nos permitte desenvolver até o máximo as nossas forças espirituaes. Rectidão de intelligência, rectidão de coração, disciplina de suas energias, foram os nossos presentes do collegio (TEIXEIRA, 1924, p. 3).

Ressalta-se que foi no Colégio Antônio Vieira que se iniciou uma grande amizade entre Anísio e o Padre Luiz Gonzaga Cabral, considerado seu grande mentor intelectual na segunda década do século XX. Luiz Gonzaga Cabral despertou em Anísio o sonho de se tornar membro da Companhia. Princípios, hábitos, atitudes e algumas posturas foram modelando Anísio ao longo da sua vida como estudante dos colégios jesuítas. Os colégios jesuítas obtiveram uma aproximação com a orientação de métodos voltados para o estudo das ciências, para além dos instruídos pelo Ratio Studiorium. Assim, Anísio cresceu e se forjou como um grande intelectual nesse ambiente educacional dos jesuítas, cujas influências são encarnadas na sua vida intelectual. Não obstante, eram ardentes os conflitos pelos quais passava na puberdade (SANTOS, 2017).

Desde o começo, no "Antônio Vieira", fora Anísio requestado pelos professores encantados pela cintilante inteligência, cada qual desejoso de integrá-lo na sua especialidade. Contou Faria Góes Sobrinho, também do Colégio, que o Padre Meyer, químico consumado, descobrira em Anísio a vocação do químico. O Padre Zimmermann o queria matemático e físico; o Padre Torrend, naturalista, nele lobrigara atento e sagaz observador da natureza; e o Padre Ferreira o desejava 
entregue à criação literária, certamente à flor da pele. O Padre Cabral desde a primeira hora quisera-o jesuíta. O velho Deocleciano, distante de qualquer convicção religiosa, sonhava com vitoriosa carreira política para o filho. [...] Desapontado, o Padre Cabral escreveu a Anísio: [...] 'Já mostrou a seu pai as páginas da sua linda dissertação sobre a Companhia [Texto 'Influência dos jesuítas' no Arquivo Mariano Acadêmico]? Faça-o, que o alegrará e a mim'. De nada valeria o apelo. Aliás não havia muito que nesse trabalho de catequese lobrigara o Padre Cabral pequena luz, motivo de 'prazer intenso', e ele escreveu a Anísio, que Ihe comunicara o momento de inclinação religiosa: 'Abafarei o meu desânimo e me atirarei ao estudo e... ao apostolado'. Ao apostolado! Este o sonho do Padre Cabral (VIANA FILHO, apud TEIXEIRA, 1989, grifos nossos).

A família refutou a ideia de ele entrar na Ordem, pois alegava que Anísio poderia ser um brilhante político. Com várias investidas do Padre Cabral para recrutá-lo à ordem jesuítica, seu pai decidiu transferi-lo para o Rio de Janeiro, para a conclusão dos estudos jurídicos, no então Distrito Federal.

O excerto a seguir, extraído de uma carta de Anísio para seus pais, corrobora a vontade em seguir um apostolado, frisando não estar preparado para o sonho de seu pai, a vida pública:

Entendi que não devia partir para o Rio sem vos deixar antes, em uma ou duas páginas de bloco, todas as razões por que tomei a resolução firme de entrar para a Companhia de Jesus e que, em conversa, não tive a sorte de expender muito claramente [...] Nunca teria o talento e as qualidades pessoais necessárias para o papel que sonhava. Com meu acanhamento, as minhas inaptidões absolutas para falar em público e uma natureza no fundo muito desanimada - as minhas ambições de apóstolo - que antes de tudo um lutador - eram quase ridículas (TEIXEIRA, 1920, grifos nossos).

No Rio de Janeiro, Anísio exaltou sua formação católica, em meio a um ambiente contrastante a sua fé:

Cristão pela graça de Deus, tive a felicidade de, desde cedo, ser educado em colégios católicos, que me souberam imprimir um grande amor à minha religião. Com os anos, à proporção que crescia dentro de mim este amor, crescia-me, também, a experiência e a justa visão das coisas. E foi indescritível a minha desolação ao perceber o menosprezo com que a maioria dos homens, considerava esta religião, única verdadeira e de onde os afastava uma educação racionalista e falsa. [...] De logo não pude mais compreender a vida como a luta pelas pequenas ambições materiais dos homens. Compreendia-a como a luta por este ideal superior da Verdade e do Bem. E já me via na imaginação de um novo apóstolo de Jesus, pregando suas idéias e seu amor e espalhando, em volta de mim, o conforto sagrado da religião. A razão viria, porém, cortar os sonhos do meu entusiasmo. O ideal ficaria o mesmo, mas, as aspirações muito menores (TEIXEIRA, 1920, grifos nossos). 
Apesar de não ter seguido a vida religiosa inaciana, o ideário jesuítico teve ressonância por um longo período de sua vida. Vale ressaltar que a amizade com o Padre Cabral persistiu mesmo com a saída de Anísio da Bahia, pois o jovem acadêmico participava como colaborador no Círculo Católico de Estudos da Mocidade Acadêmica ou mesmo na Congregação Mariana Acadêmica, fundada em 1916, cuja intenção era a perseverança do ideário cristão inaciano entre os alunos das universidades, como se observa na imagem a seguir:

Figura 1 - Colaboração de Anísio Teixeira para o Círculo Católico, em 1919

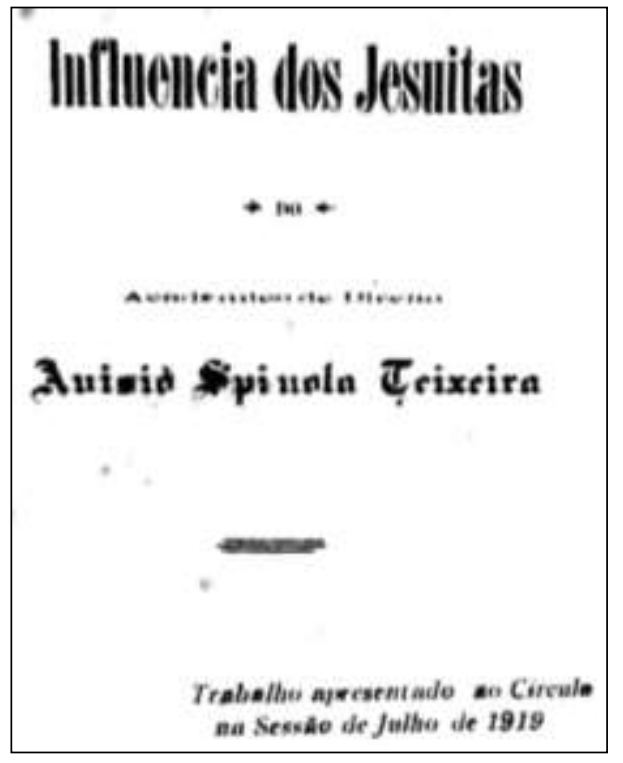

Fonte: Teixeira (1925).

Santos (2017, p. 95) sinaliza que a influência jesuítica foi hegemônica nos fazimentos de Anísio até meados de 1926, materializados nas publicações de: “A Propósito da Escola Única (novembro, 1924), 'À Sombra do Catolicismo', 'Acies Ordinata' (maio/1925) e 'Jacques Riviére' (maio/1926), [...] 'O alto sertão na Bahia', [...] em 1926”. Ressalta-se que, em 1925, Anísio viajou para a Europa (Espanha, Bélgica, Itália e França), para observar os sistemas escolares (GONDRA, 2000), trazendo-lhe, no campo pessoal, experiências profanas,

deixando-Ihe sensações dispersivas relativas à sua fé, durante quatro meses de elegante vagabundagem [...] Pressente a necessidade de renovação. O mundo 'profano' ao qual estava mergulhado agora Ihe inquietava o espírito. Suas antigas concepções pareciam não mais dar conta dessa nova realidade [...] Evidencia-se, desde logo, o deslocamento ou revisão do seu pensamento. Sua crença no catolicismo 
esvaia-se cada vez mais; no que se refere à política, já aceita a possibilidade da descentralização do poder; no plano pedagógico, admite a forte aproximação americana e o afastamento do sistema europeu (SANTOS, 2017, p. 113, grifos nossos).

Sobre essa viagem à Europa Anísio Teixeira registrou em seu diário que ficou com muitas dúvidas e lhe gerou uma crise espiritual. Warde (2005), ao tematizar a respeito dessa experiência vivenciada por Anísio Teixeira, assevera que a modernidade que ele havia visto em Paris o deixou contrariado pela artificialidade das luzes parisienses que parecia esconder a escuridão uma crise da espiritualidade do homem moderno.

Destarte, percebemos como alguns dos elementos do distanciamento do pensamento jesuíta foram: o grande conflito pessoal de Anísio; a oposição familiar; e a atitude de aceitação das "terríveis mudanças que o progresso estava impondo à vida humana e ao processo de educar" (TEIXEIRA, 1977, p. 160). E prossegue:

Todo o nosso passado, os nossos mais caros preconceitos, os nossos hábitos mais queridos, a nossa agradável vida paroquial, tudo isto se levanta contra o tumulto e a confusão de uma mudança profunda da cultura, como a que estamos sofrendo. Contudo, a mocidade está aceitando esta mudança, é verdade que um tanto passivamente, mas sem nada que lembre a nossa inconformidade. A mudança, todos sabemos, é irreversível. Só conseguiremos restaurar-lhe a harmonia, se conseguirmos construir uma educação que a aceite, a ilumine e a conduza num sentido humano (TEIXEIRA, 1977, p. 160).

Não obstante, Anísio, mesmo em fases mais pragmatistas, não deixou de valorizar sua educação jesuítica. Em 1952, em entrevista conduzida por Jaime Abreu (cf. LOURENÇO FILHO, 2001), a primeira pergunta questionava sobre seu cabedal cultural para o exercício de suas funções públicas profissionais. Anísio enfatizou que sua cultura geral é consequência da formação jesuíta ${ }^{12}$, dos cinco anos de Literatura e Direito no Rio de Janeiro e da humildade e ardor religioso de jovem líder católico.

\footnotetext{
${ }^{12}$ Cabe salientar a importância desse depoimento, já que, conforme Gondra (2000, p. 3), "Anísio não escreveu suas memórias. Não se preocupou ou não teve tempo, oportunidade ou disposição de arquivar sua própria vida".
} 


\section{Considerações finais}

O estudo sobre Anísio Teixeira deve ser compreendido a partir de uma interlocução clara entre a visão que ele detinha sobre o processo histórico, político e social no país, bem como sua relação incondicional com a educação jesuítica obtida nos colégios da Ordem.

Verificamos, ao longo do texto, que Anísio teve um percurso formativo bastante amplo e adensado, ao fazer parte dos colégios jesuítas durante sua adolescência e mocidade. Ao receber um processo educativo que era compreendido com cadeiras de Literatura, Letras e da área de Exatas, pôde construir um conjunto de saberes diferenciados que, muito provavelmente, influenciaram-no a pensar novas propostas educacionais no Brasil no século XX.

Pudemos constatar que, em sua vida pública, Anísio militou em prol de uma educação mais includente e democrática. Assumiu cargos com grande notoriedade e protagonismo. Constituiu "nichos epistemológicos" ao tratar da educação e foi um dos pioneiros ao trazer, para o debate, a questão de uma concepção de educação integral como potencialidade de desenvolvimento das faculdades intelectuais, morais, sociais e físicas para o indivíduo, a partir do Manifesto Escolanovista.

Seus fazimentos na área da educação são um legado que rememoriamos sempre ao falar em uma proposta de educação sem privilégios, destinada democraticamente para todos. Essa bandeira de luta foi e permanece enaltecida por diversos grupos que se mobilizam em prol da qualidade na educação.

$\mathrm{Na}$ tentativa de realizar uma pesquisa memorialística sobre Anísio Teixeira, garimpamos documentos que fizeram parte dessa conjuntura histórica no início do século XX. Tanto o discurso realizado por Anísio Teixeira no Colégio Antônio Vieira na Bahia, bem como as "Conferências Pedagógicas”, realizadas pela Ordem Inaciana, apontaram vestígios da sua formação ligados à temática da Educação Integral. Sua vivência com pragmatistas e escolanovistas, tanto no Brasil, quanto no exterior, cimentaram uma concepção, tida como liberal, de uma Educação Integral democrática, laica, sem privilégios, e não focada em filhos da elite, que, tradicionalmente, estavam presentes nos colégios jesuítas. 
Podemos inferir que Anísio Teixeira recebeu uma formação inaciana, cuja tessitura foi desenvolvida por um cabedal de normas, condutas, conhecimentos diferenciados e hábitos que o conduziram para um aprimoramento do seu ser. Ao estudar nos colégios jesuítas, ele pôde receber uma educação privilegiada como indutora de desenvolvimento, progresso e sensibilidade à causa dos mais desvalidos.

$\mathrm{Na}$ tentativa de problematizar o "teimoso passado" e o "insistente futuro", foi desenvolvendo seus estudos com um arcabouço apreendido durante a longa jornada na juventude. Seus mestres jesuítas são lembrados em documentos e cartas que promoveram a interlocução investigativa deste material.

Vale ressaltar que, durante as pesquisas, observamos um notório apagamento dessa memória Anisiana no período em que conviveu com os jesuítas. Ainda é prematuro asseverar os porquês desse apagamento, entretanto, apontamos que os "nichos disciplinares" das academias estigmatizam esse período como algo indiferente, conservador e tradicionalista. Avaliamos que os vestígios jesuíticos de Anísio Teixeira sejam relevantes para a elucidação de questões que pairam na roda do pensamento educacional brasileiro.

\section{Referências}

AZEVEDO, F. A Missão Portuguesa da Companbia de Jesus no Nordeste (1911 -1936). Recife: Fundação Antonio dos Santos Abranches, 1986.

BOSI, E. Memória e sociedade: lembrança dos velhos. 3. ed. São Paulo: Companhia da Letras, 1994.

BRANDÃO, Z.; MENDONÇA, A. W. Uma tradição esquecida: por que não lemos Anísio Teixeira? 2. ed. Rio de Janeiro: Forma e Ação, 2008.

BRASIL. Ministério da Educação. Secretaria de Educação Continuada, Alfabetização e Diversidade. Educação Integral: texto referência para o debate nacional. Série Mais Educação. Brasília, DF, MEC, 2009. Disponível em: $<$ http://portal.mec.gov.br/dmdocuments/cadfinal_educ_integral.pdf $>$. Acesso em: 20 maio 2019.

BRITTO, L. M. G.; MENEZES, J. M. F. Apontamentos sobre reflexões que emergem do discurso proferido por Anísio Teixeira na Festa dos Antigos Alumnos do Colégio Antônio Vieira, 1924. In: SOUSA, C. A. M.; CAVALCANTE, M. J. M. (orgs.). Os jesuitas no Brasil: entre a colônia \& a república. Brasília: Liber Livro, 2016. p. 193-213.

CASTRO, C. A.; SILVEIRA, A. S. Civilidade, educação e a Companhia de Jesus (Séc. XVIXVIII). In: SOUSA, C. A. M.; CAVALCANTE, M. J. M. (orgs.). Os jesuitas no Brasil: entre a colônia \& a república. Brasília: Liber Livro, 2016. p. 21-44. 
COELHO, L. M. C. C.; MENEZES, J. S. S. Tempo Integral no ensino fundamental: ordenamento constitucional-legal em discussão. In: ANPED. $30^{a}$ Reunião anual da ANPED: 30 anos de pesquisa e compromisso social. Rio de Janeiro: ANPED, 2007.

GONDRA, J. Anísio Teixeira - lugares de lembrar. Revista Teias, Rio de Janeiro, v. 1, n. 1, jan./ jun. 2000, p. 1-11.

GUMIEIRO, F. As ordens religiosas e a construção sócio-política no Brasil: Colônia e Império. Tuiuti: Ciência e Cultura, Curitiba, p. 63-78, 2013.

HEYMANN, L. Q. Os fazimentos do arquivo Darcy Ribeiro: memória, acervo e legado. Estudos históricos, Rio de Janeiro, n. 36, p. 43-58, jul./dez. 2005.

LACOUTURE, J. Os Jesuitas. Os Conquistadores. V. 1, Porto Alegre: L\&PM Editores, 1994.

LEITE, S. História da Companbia de Jesus no Brasil. Rio de Janeiro: Instituto Nacional do Livro, 1949.

LOURENÇO FILHO, R. Caminhos e encontros: correspondências entre Anísio Teixeira e Lourenço Filho. In: MONARCHA, C. (org.). Anisio Teixeira: a obra de uma vida. Rio de Janeiro: DP\&A, 2001. p. 193-223.

LOYOLA, I. Autobiografia do Santo Inácio de Loiola. Trad. António José Coelho. Braga: Editorial A. O., 2005.

MALLMANN, A. N. Retrato sem retoques das missões guaranis. Porto Alegre: Martins Livreiro, 1986.

MATOS, S. C. M. Grandes pensadores tensionando o I Programa Especial de Educação (1983-1986). Cadernos de História da Educação, v. 15, n. 3, p. 1248-1269, set./dez. 2016. Disponível em: <http://dx.doi.org/10.14393/che-v15n3-2016-17>. Acesso em: 12 jan. 2019.

MATOS, S. C. M. Memórias e diálogos com a Educação Integral: o legado de Maria Yedda Leite Linhares (1983-1986). 2017. 209 f. Tese (Doutorado em Educação) - Faculdade de Educação, Universidade do Estado do Rio de Janeiro, Rio de Janeiro, 2017.

MENDONÇA, A. W. O CBPE: um projeto de Anísio Teixeira. In: BRANDÃO, Z.; MENDONÇA, A. W. Uma tradição esquecida. Por que não lemos Anísio Teixeira? 2. ed. Rio de Janeiro: Forma e Ação, 2008. p. 41-63.

RENAUD, M. (org.). Missão da Companbia de Jesus do Norte do Brasil. Conferências pedagógicas. São Paulo: Typografia Brasil de Rothschild \& Cia, 1921.

SANTOS, D. T. Anísio Teixeira: vida e pensamento pedagógico. 2017. 235f. Tese (Doctorado Educación y Sociedad) - Universitat de Barcelona, Barcelona, 2017.

SAVIANI, D. História das ideias pedagógicas no Brasil. São Paulo: Autores Associados, 2008.

SOUSA, C. A. M.. Fé, Ciência e Educação: Os Jesuítas da Província Portuguesa no Retorno ao Nordeste do Brasil no Início do Século XX. In: CAVALCANTE, M. J. M., HOLANDA, P. H. C.; LUSTOSA, F. G.; DIAS, R. B.(orgs.). Histórias de Pedagogia, Ciência e Religião: discursos e correntes de cá e do além-mar. Fortaleza: Edições UFC, 2016. p. 287-300.

SOUSA, C. A. M. Corpos viris e virtuosos: anotações sobre a educação do Colégio Antônio Vieira na Salvador das primeiras décadas do século XX. In: CAVALCANTE, M. J. M., HOLANDA, P. H. C.; JUCÁ; G. N. M. (Orgs.).Histórias de Corpo, Religião e Educação. Fortaleza: Edições UFC, 2017. p. 175-190. 
TEIXEIRA, A. Carta a Anna Spinola Teixeira e Deocleciano Pires Teixeira. Caetité, 25 mar. 1920. Disponível em: <http://www.bvanisioteixeira.ufba.br/back.html>. Acesso em: 26 jan. 2019.

TEIXEIRA, A. Discurso pronunciado por Anísio Teixeira no Colégio Antonio Vieira. Salvador, 1924. Disponível em: ,www.fgv.br/cpdoc/acervo/arquivo-pessoal/AT/textual/discursopronunciado-no-colegio-antonio-vieira-por-ocasiao-da-festa-de-reencontro-dos-ex-alunosbahia. Acesso em: 20 fev. 2019.

TEIXEIRA, A. Influência dos Jesuítas. In: Congregação Mariana Acadêmica. Arquivo Mariano Acadêmico. Bahia: Imprensa official do Estado, 1925.

TEIXEIRA, A. Por que Escola Nova? Boletim da Associação Babiana de Educação, Salvador, n. 1, p. 2-30, 1930. Disponível em: <http://www.bvanisioteixeira.ufba.br/artigos/nova.htm>. Acesso em: 05 maio 2019.

TEIXEIRA, A. Bases da teoria lógica de Dewey. Revista Brasileira de Estudos Pedagógicos, Rio de Janeiro, v. 23, n. 57, p. 3-27, jan./mar. 1955.

TEIXEIRA, A. Plano de Construções Escolares de Brasília. Revista Brasileira de Estudos Pedagógicos, Rio de Janeiro, v. 35, n. 81, p. 195-199, jan./mar. 1961.

TEIXEIRA, A. Educação e o mundo moderno. São Paulo: Ed. Nacional, 1977.

TEIXEIRA, A. Ensino superior no Brasil: análise e interpretação de sua evolução até 1969. Rio de Janeiro: Editora FGV, 1989. Disponível em: <http://www.bvanisioteixeira.ufba.br/livros/chama_adicionais.htm>. Acesso em: 05 dez. 2018.

TEIXEIRA, A. Educação é um direito. Rio de Janeiro: UFRJ, 1996.

TEIXEIRA, A. Pequena introdução à filosofia da educação: a escola progressiva ou a transformação da escola. Rio de Janeiro: Ed. UFRJ, 2007.

TOLEDO, C. A. A.; RIBAS, M. A. A. B.; SKALINSKI JUNIOR, O. (Org.). Origens da educação escolar no Brasil colonial. v. 1. Maringá: Eduem, 2012.

WARDE, M. J. John Dewey through Anísio Teixeira: or Reenchantment of the World. In: POPKEWITZ, T. (ed.). Inventing the Modern Self and John Dewey: Modernities and the Traveling of Pragmatism in Education. Chennia, Palgrave 2005. p. 214-229.

RECEBIDO: $30 / 06 / 2019$

APROVADO: $12 / 11 / 2019$

RECEIVED: 06/30/2019

APPROVED: $11 / 12 / 2019$

RECIBIDO: $30 / 06 / 2019$

APROBADO: $12 / 11 / 2019$ 